Article

\title{
Fuzzy Multicriteria Decision-Making Model (MCDM) for Raw Materials Supplier Selection in Plastics Industry
}

\author{
Chia-Nan Wang ${ }^{1, *}$, Van Thanh Nguyen ${ }^{2}$, Jiin-Tian Chyou ${ }^{3}$, Tsung-Fu Lin ${ }^{3, *}$ and \\ Tran Ngoc Nguyen ${ }^{4}$ \\ 1 Department of Industrial Engineering and Management, National Kaohsiung University of Science and \\ Technology, Kaohsiung 80778, Taiwan \\ 2 Department of Logistics and Supply Chain Management, Hong Bang International University, \\ Ho Chi Minh City 72320, Vietnam; thanhnv@hiu.vn \\ 3 Department of Management Information Systems, National Chengchi University, Taipei 11605, Taiwan; \\ jchyou@nccu.edu.tw \\ 4 Department of Industrial Systems Engineering, CanTho Universiy of Technology, CanTho 900000, Vietnam; \\ trngng96@gmail.com \\ * Correspondence: niceray4731@gmail.com (C.-N.W.); 100356504@nccu.edu.tw (T.-F.L.)
}

Received: 25 September 2019; Accepted: 11 October 2019; Published: 16 October 2019

\begin{abstract}
To be able to compete in the domestic plastic industry, small and medium-sized enterprises producing plastic need to proactively find the supply of raw materials, avoiding shortages like in the previous years. Purchasing is extremely important and will create a competitive advantage with competitors in the market, so finding suppliers will determine the success in the later stages of the production chain. With the development of the current information system, selection and evaluation have become important in order to achieve effective decision-making through optimal options. In this study, the authors provide a new approach for decision-makers in evaluating and selecting suppliers, which is formulated based on the supply chain operation reference (SCOR) model, fuzzy analytic network process (FANP), and VIseKriterijumska Optimizacija I Kompromisno Resenje (VIKOR). The contribution of this research is to propose a multicriteria decision-making model (MCDM) for raw material supplier selection in the plastic industry. This research also provided a useful guideline for supplier selection in other industry.
\end{abstract}

Keywords: supplier selection; MCDM; fuzzy theory; FANP; VIKOR; plastics industry

\section{Introduction}

Along with the strong development of science and technology and the trend of globalization, supply chain and logistics activities from production to consumption have played an increasingly important role in capacity competition of industries in general and plastics industry in particular. With a production growth rate of $16-18 \%$ per year, second only to telecommunications and textile industry, the plastic industry is considered a dynamic industry in Vietnam's economy [1]. Selection of suppliers, which is the first step in the product implementation process, starting from the purchase of raw materials to the end of product delivery, is considered to be a deciding factor for companies looking forward to success in today's competitive conditions [2]. The process of supplier selection can be considered as the multi criteria decision-making (MCDM) to find an optimal solution for supplier selection [3].

The problem of decision-making becomes more complicated when there are many groups of people and experts involved in the decision-making process. In order to select suppliers with objectivity, 
avoiding subjective factors such as human factors, documents, relationships, etc., that is vague and incomplete in making decisions is crucial [4]. Moreover, most previous studies have assumed that each criterion cluster in the method they use has equal weight to solve the problem with a weighted hyper matrix $[5,6]$. Therefore, previous studies have not exploited the advantages and disadvantages of the models or methods they have applied. With the development of the current information system, selection and evaluation have become important to achieve effective decision-making through optimal options [7].

According to the Vietnam Plastics Association (VPA), each year, Vietnam's plastic industry needs about 5 million tons of plastic materials and hundreds of additives, while domestic production can only supply about 900,000 tons of raw materials/year. According to the data from the General Department of Customs, Vietnam must import 4.54 million tons of plastic materials worth nearly $\$ 6.3$ billion, up $15.7 \%$ over the same period.

The reliance on imported plastic materials not only causes businesses to stagnate capital because of stockpiling raw materials, but also has potential risks on exchange rates and world oil prices. Every time the VND/USD exchange rate increases, input costs of plastic businesses will increase accordingly.

The primary goal of this research is to propose a multi criteria decision-making model (MCDM) for raw material supplier selection in plastic industry and also provide a useful guideline for supplier selection in other industry.

In this study, the proposed model provides a new approach for decision-makers in evaluating and selecting suppliers, which is formulated based on the supply chain operation reference (SCOR) model, fuzzy analytic network process (FANP), and VIseKriterijumska Optimizacija I Kompromisno Resenje (VIKOR).

This paper provides research background, motivation, goals to implement, a review of relevant published scientific articles, including proposed models of VIKOR, FANP, SCOR Metrics. In order to verify the research model, the content of case study presents the evaluation criteria, the application of SCOR Metric, FANP method, and VIKOR method, in model building and data processing. Discussion and results are presented in the end of this article.

\section{Literature Review}

Along with the performance attributes, the main criteria and the sub-criteria selected for the evaluation and supplier selection in this study are presented in Table 1.

Table 1. The main and sub-criteria are defined based on the supply chain operation reference (SCOR) model.

\begin{tabular}{|c|c|c|}
\hline Main Criteria & Subcriteria & Preference \\
\hline Reliability & $\begin{array}{c}\text { Delivery performance } \\
\text { Fulfill the full orders } \\
\text { Quantity delivered on an entire order } \\
\text { Quality of goods }\end{array}$ & {$[8-20]$} \\
\hline Responsiveness & $\begin{array}{c}\text { Total response time to customers } \\
\text { Delivery time } \\
\text { Return products time }\end{array}$ & {$[8,10-16]$} \\
\hline Ability & $\begin{array}{l}\text { Ability to meet delivery demand } \\
\text { Ability to receive returns products } \\
\text { Ability to produce new raw materials }\end{array}$ & {$[8,10-12,14-16,20]$} \\
\hline Costs & $\begin{array}{c}\text { Material cost } \\
\text { Maintenance cost } \\
\text { Transportation costs }\end{array}$ & {$[8,11-14,16,19]$} \\
\hline Asset management efficiency & $\begin{array}{l}\text { Financial situation of suppliers } \\
\text { Payment term allowed } \\
\text { Revenue over a year } \\
\text { Inventory amount of suppliers }\end{array}$ & {$[10,11,14,16,17,20]$} \\
\hline
\end{tabular}


Supply chain operation reference was proposed in 1996 [8,9] by Theodore Pittiglio, Robert Rabin, Robert Todd, and Michael McGrath [10]. Specifically, the SCOR model describes business activities related to meeting customer needs, including planning, sourcing, execution, delivery, and return. The use of models includes analyzing the current state of company processes and goals, quantifying performance, and comparing company performance with benchmarking data. SCOR is developed from a set of best practices data and information that companies can use in building and evaluating their supply chain performance [8,9]. This model allows companies to conduct comprehensive analysis based on practically all aspects of their supply chain by providing a complete set of process, performance, and real-life metrics best practices in the industry [10]. The performance attributes of SCOR data are shown below [11]. The SCOR's process includes: definition of process components, input-output, process performance data, selected best supplier $[8,12-15]$. SCOR uses historical supply chain data to see how it works and develops, which defines the five general performance attributes and three measurement levels that analysts offer $[13,15]$.

The propositional logical reasoning, so-called primitive or basic logic with two values, true or false [1,0], did not solve all the problems of complex problems that arise in practice [21]. In decisive situations with lots of choices with multiple criteria set out, such as supplier selection with a range of supplier lists and multiple factors to evaluate with small selection criteria subject to subjective factors by decision-makers [21,22].

Since the fuzzy theory was published, it has been developed and applied widely in all technical specialties. From 1980 onward fuzzy theory marked a new turning point, when applied by many researchers in data analysis and decision-making support in Europe [4,22]. In the mid-1980s, industrial engineering applied fuzzy theory to almost all fields related to industrial engineering such as fuzzy prediction, fuzzy decision-making, linear planning, fuzzy inventory management, fuzzy quality control, fuzzy data modulation, fuzzy engineering economics, fuzzy specialist systems, fuzzy learning factors [21,23]. Fuzzy theory is also applied by researchers in location planning. Evans et al. in 1987 introduced a layout plan based on fuzzy theory to solve the problem of position design of each item [24]. Inputs for site design including distance and importance levels are modeled by linguistic variables [24].

B. Song et al. (1996) applied fuzzy theory to the model of parameters and damage caused by earthquakes. Damage characteristics of buildings with different distances from epicenter were considered based on data obtained from nine earthquakes in China [25]. J. Yang et al. in 2003 applied fuzzy theory to calculate the optimal operation of the excavator in order to accurately estimate the construction time [26].

When considering $X$ in a set of $x$ elements, fuzzy sets are the sets represented by the member function $\mu_{M}(x)$ expressing the ability for $x$ to belong to the set $M$. The values represent the membership level of an element $x$ in the range [0,1] [4,23]. The fuzzy number concept was proposed by Lotfi Zadeh to describe an amount whose value cannot be accurately measured $[4,21,24]$. There are many types of fuzzy numbers like triangular fuzzy numbers, trapezoidal fuzzy numbers, L-R fuzzy numbers, Gaussian fuzzy numbers, and exponential fuzzy numbers, but triangular fuzzy number (TFN) is most commonly used [21-23].

Analytic network process (ANP) was proposed by Saaty in 1996 [27]. ANP is an improved version of the analytic hierarchy process (AHP). ANP helps to conduct analysis and evaluation of network effects or in other words, interconnection between criteria and criteria clusters [27]. ANP overcomes the disadvantages when considering hierarchical relationship $[27,28]$, namely, one-way rectification of the factors and not taking into account the relationships among the factors such as the AHP predecessor method [28]. ANP has been applied in many specific fields, making it easier to solve decision-making problems by building relationships between different goals, criteria, options and establishing a comparison matrix of criteria for an optimal option [28,29]. However, there are still many shortcomings that ANP method has not solved, such as problems with uncertainty when performing matrix comparison matrix $[27,29]$. Dividing the decision problem into subproblems, 
the pairs of comparisons increase the number creating disadvantages in the evaluation process [15]. The traditional ANP method is incomplete because it has not yet shown data clearly to produce accurate results $[27,29,30]$. One way to overcome the shortcomings in ANP method is to integrate fuzzy set model into network analysis to support multi-criteria decisions in uncertain environments $[27,28,30]$.

VIseKriterijumska Optimizacija I Kompromisno Resenje (VIKOR) [31] is a method of multi-criteria decision-making (MCDM) or a method of analyzing multi-criteria decisions. It was originally developed by Serafim Opricovic to address decisive issues with conflicting criteria, and it is impossible to resolve the assumption that compromise is acceptable for conflict resolution, the decision-maker wants the solution is closest to the ideal and the solution is evaluated according to the ideal so that all criteria are set [32]. VIKOR ranks the alternatives and identifies the solution named as the closest compromise to the ideal. The VIKOR method provides a complete view of the suitability of any option and helps to bring subjective elements out of the equation [7,31-33]. VIKOR method has many variants such as: VIKOR multi-criteria compromise method, VIKOR comparative analysis method, fuzzy VIKOR method, theoretical value of regret based on VIKOR method, method VIKOR about [33,34].

In the VIKOR method, the ranking of alternatives performance relative to a set of criteria is quantified as a fairly clear value [35-38]. But in many cases, clear data is not enough to model real-world situations. In addition, in the event of conflicting situations or criteria, decision-makers must also consider inaccurate or ambiguous data [35-38]. To address the data inaccuracies or ambiguities, a combination of VIKOR with decision support methods are used in research papers [35].

In an effort to continually refine production, companies are constantly looking for high-performance suppliers to keep their production constantly running. [28] The selection of high-performance suppliers is difficult to evaluate $[13,34,36]$. The assessment and selection of suppliers is a matter of multi-criteria decision-making (MCDM), in which decision-makers face both qualitative and quantitative factors $[13,39]$. The most prominent is the research, reviewing the multi-criteria decision-making approach to assessing and selecting green suppliers by Sarkis et al. [40]. This shows that the problem of supplier selection becomes important and affects mathematicians through research and practical applications.

However, in the decision-making process, there are sometimes subjective factors, depending on decisions made by experts or management $[3,6]$. Mandatory selection and evaluation requires strong access and analysis with the best decision-support tools, capable of solving many criteria [34]. In 1980, L. Pun and his colleagues conducted a survey to support computer systems in the field of high-tech manufacturing. The authors set out criteria for decentralization in buying and choosing houses [41]. In the following years, the selection and evaluation of suppliers was of interest and development by many researchers; in particular, Weber and his colleagues gave a comprehensive view of the criteria of the researchers and participants purchase by making the level of decision-based importance to assess and select suppliers [42].

Both FAHP and FANP methods are not just a simple mathematical method, the two above mathematical models are applied to analyze, evaluate, and select locations, suppliers, etc., provided based on FANP model of Ahmad Dargi et al. [43]. The study of B. Edebilli and Turan Erman Erkan is based on FAHP methodology in ranking suppliers [44]. However, FANP method still has many shortcomings [28]. To increase decision accuracy researchers have combined FANP with other mathematical methods to make the decision-making process clear $[28,45]$.

To evaluate suppliers such as using the VIKOR method to evaluate, rank, and select the optimal supplier $[45,46]$ based on the satisfaction factor between supply and demand is essential to maximize the index when listing to choose [46]. However, the VIKOR method also has its limitations, when expressing data is not clear in some real-life situations, resulting in low accuracy [6]. Krzysztof PiaseckiE and Ewa Roszkowska applied ordered fuzzy numbers in ranking linguistically evaluated negotiation offers. The main purpose of this paper is to investigate the application potential of ordered fuzzy numbers (OFN) to support evaluation of negotiation offers. The simple additive weighting (SAW) and the technique for order of preference by similarity to ideal solution (TOPSIS) methods are extended to the case when linguistic evaluations are represented by OFN [47]. Typically, the research combines FANP 
and VIKOR in the selection of sustainable transformation technology in the field of agriculture [48]. In addition, the study combines an ANP model with VIKOR [49-51] in the application of the selection of sustainable suppliers in the field of importation by M.Abdel-Baset and his colleagues [49].

However, to assess objectively in the selection of suppliers, in addition to selection and evaluation based on supplier's characteristics, it is also based on the supplier's performance factor [40]. To avoid the lack of evaluation, Francisco Rodrigues Lima-Junior and Luiz Cesar Ribeiro Carpinett combined SCOR and TOPSIS [7,13], in which SCOR provides a standard performance table and TOPSIS ranks and evaluates the supplier list $[13,40]$. In addition, the SCOR supply chain reference model is also applied in many supply chain-related fields, typically the selection of suppliers in the oil and gas sector based on a combination of three models, SCOR, AHP, TOPSIS $[27,30,40]$.

\section{Methodology}

\subsection{Research Graph}

In this research, the authors proposed an MCDM model, including SCOR metrics, FANP and VIKOR model, for supplier evaluation and selection in plastics industry. There are three main steps in this paper, as shown in Figure 1.



Figure 1. Research graph.

Step 1: Determine key criteria and sub-criteria for a comprehensive assessment of the potential supplier. At this stage, the identification of key criteria and sub-criteria is based on a review of the literature, SCOR metrics and scientific reports related to the content of the research to determine the necessary criteria for the topic. 
Step 2: Hybrid fuzzy set theory into the ANP model is the most effective tool for addressing complex problems of decision-making, which has a connection with various qualitative criteria. There are ten suppliers that are highly effective for providing plastic raw materials. In this step, an FANP is proposed to identify the weight of all criteria.

Step 3: For ranking potential suppliers list, VIKOR model is used in the final stage. VIKOR ranks alternatives and determines the solution named compromise that is the closest to the ideal.

\subsection{Methodology}

\subsubsection{Fuzzy Set}

There are many types of fuzzy numbers like triangular fuzzy numbers, trapezoidal fuzzy numbers, L-R fuzzy numbers, Gaussian fuzzy numbers, and exponential fuzzy numbers, but triangular fuzzy number (TFN) is most commonly used [21-23]. Triangular fuzzy numbers are represented by a set of three real numbers $(a, b, c)$ and $(a<b<c)$, perform via member function $\widetilde{F}=\left(F^{1(y)}, F^{r(y)}\right)=(a-(b-a) y$, $c+(b-c) y), y \in[0,1]$. The $\sim$ symbol is set to present fuzzy sets. Triangular fuzzy numbers as shown in Figure 2.

$$
\mu_{\widetilde{F}}(x)=\left\{\begin{array}{cc}
\frac{(x-a)}{(b-a)} & a \leq x \leq b \\
\frac{(c-x)}{(c-b)} & b \leq x \leq c \\
0 & \text { others }
\end{array}\right.
$$

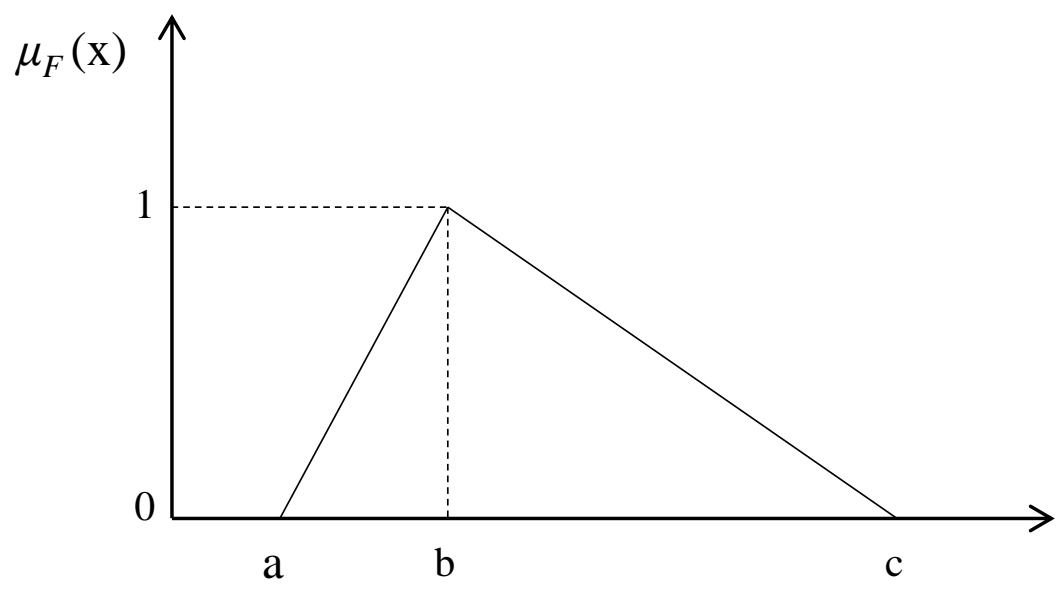

Figure 2. Triangular fuzzy numbers [21,23].

\subsubsection{FANP Model}

The process of implementing FANP is as follows [27-30]:

Step 1: Building the FANP model.

Building FANP model structure is based on the criteria defined in the SCOR model. Criteria are interconnected and interrelated from the main and subcriteria.

Step 2: Prepare the fuzzy comparison matrix.

The results of the questionnaire from experts were converted into triangular fuzzy numbers based on Tables 1 and 2. 
Table 2. Fuzzy comparison matrix.

\begin{tabular}{cccccc}
\hline $\mathbf{C}$ & $\mathbf{A}_{1}$ & $\mathbf{A}_{2}$ & $\mathbf{A}_{3}$ & $\ldots$ & $\mathbf{A}_{n}$ \\
\hline $\mathrm{A}_{1}$ & 1 & $\mathrm{a}_{12}$ & $\mathrm{a}_{13}$ & & \\
$\mathrm{~A}_{2}$ & $1 / \mathrm{a}_{12}$ & 1 & $\mathrm{a}_{23}$ & & \\
$\mathrm{~A}_{3}$ & & & 1 & & \\
$\ldots$ & & & & 1 & \\
$\mathrm{~A}_{\mathrm{n}}$ & & & & & 1 \\
\hline
\end{tabular}

The pair comparison matrix of fuzzy numbers is used to make pair-to-match comparisons between criteria. The pairwise comparison matrix is presented as follows:

$$
\widetilde{W_{C h}}=\left[\begin{array}{cccc}
1 & C_{2} & \cdots & \widetilde{a_{1 N h}} \\
\widetilde{a_{21 h}} & 1 & \cdots & \widetilde{a_{2 N h}} \\
\cdots & \cdots & \widetilde{a_{i j h}} & \cdots \\
\widetilde{a_{N 1 h}} & \widetilde{a_{N 2 h}} & \cdots & 1
\end{array}\right], \quad i=1,2, \ldots N, j=1,2, \ldots N
$$

The value $\widetilde{a_{i j}}$ compares the pair set with the criteria $i$ and $j$ determined by expert $h$.

Step 3: Prepare matrices comparison matrices.

Summarize the opinions of experts using the average method. For experts $h$, the numerical mean gives a comparison value between pairs of criteria $i$ and $j$ :

$$
\widetilde{f_{i j}}=\left(\widetilde{a_{i j 1}} \times \ldots \times \widetilde{a_{i j h}}\right)^{1 / k}=\left(l_{i j}, m_{i j}, r_{i j}\right), i=1,2, \ldots N, j=1,2, \ldots N
$$

Step 4: Clear the matrix of pairwise comparison of pseudo-fuzzy triangles as follows: [52,53].

$$
t_{\alpha, \beta}\left(\bar{\alpha}_{i j}\right)=\left[\beta \times g_{\alpha}\left(L_{i j}\right)(1-\beta) \times g_{\alpha}\left(U_{i j}\right)\right] 0 \leq \beta \leq 1 ; 0 \leq \alpha \leq 1
$$

where $\alpha$ represents an uncertain environment, $\beta$ shows that the assessor's attitude is fair

$$
\begin{gathered}
g_{\alpha}\left(L_{i j}\right)=\left(M_{i j}-L_{i j}\right) \times \alpha+L_{i j} \\
g_{\alpha}\left(U_{i j}\right)=U_{i j}-\left(U_{i j}-M_{i j}\right) \times \alpha
\end{gathered}
$$

When taking symmetry through the diagonal matrix we have:

$$
t_{\alpha, \beta}\left(\bar{\alpha}_{i j}\right)=\frac{1}{t_{\alpha, \beta}\left(\bar{\alpha}_{i j}\right)}
$$

Step 5: Calculate largest private value and check for consistency index.

$$
W_{c} \times w_{c}=\lambda_{\max } \times w_{c}
$$

where $W_{c}$ is an aggregated match from the criteria, $w_{\mathcal{c}}$ is the eigenvalue vector, and $\lambda_{\max }$.

Consistency index (CI) and random index (RI) are calculated by:

$$
\begin{gathered}
C I=\frac{\lambda_{\max }-N}{N-1} \\
C R=\frac{C I}{R I}
\end{gathered}
$$

For each n-level comparison matrix, Saaty experimented to create random matrices and calculate the RI index corresponding to the criteria as shown in the Table 3 below [27]. 
Table 3. Random index value corresponding to the norm.

\begin{tabular}{ccccccccccc}
\hline $\mathbf{N}$ & $\mathbf{1}$ & $\mathbf{2}$ & $\mathbf{3}$ & $\mathbf{4}$ & $\mathbf{5}$ & $\mathbf{6}$ & $\mathbf{7}$ & $\mathbf{8}$ & $\mathbf{9}$ & $\mathbf{1 0}$ \\
\hline $\mathrm{R}$ & 0 & 0 & 0.52 & 0.90 & 1.12 & 1.24 & 1.32 & 1.41 & 1.45 & 1.49 \\
\hline
\end{tabular}

If the inconsistency ratio of $\mathrm{CR}$ is greater than 0.1 which means the value is inconsistent, ask the expert to modify the answer sheet and perform the calculation again.

Step 6: Calculate super matrix as Table 4.

Table 4. Super matric.

\begin{tabular}{ccc}
\hline $\mathbf{0}$ & $\mathrm{U}_{12}$ & $\mathbf{0}$ \\
\hline $\mathrm{U}_{21}$ & $\mathrm{U}_{22}$ & $\mathrm{U}_{23}$ \\
0 & 0 & 0 \\
\hline
\end{tabular}

Step 7: Calculate the upper and lower limit of the matrix and have the results.

\subsection{VIKOR Model}

Step 1: From the given decision matrix, determine the value $\left(f_{i j}\right)_{\max }$ and $\left(f_{i j}\right)_{\min }$ of all criteria.

Step 2: The weights of the sub-criteria are determined using either analytical hierarchical procedure or an entropy method.

Step 3: Calculate the value of $S_{i}$ and $R_{i}$ by:

$$
\begin{gathered}
S_{i}=L_{1, i}=\sum_{j=1}^{A}\left[w_{j}\left(\left(f_{i j}\right)_{\text {max }}-f_{i j}\right) /\left(\left(f_{i j}\right)_{\text {max }}-\left(f_{i j}\right)_{\text {min }}\right)\right] \\
R_{i}=L_{i, \infty}=\operatorname{Max}\left\{w_{j}\left[w_{j}\left(\left(f_{i j}\right)_{\text {max }}-f_{i j}\right) /\left(\left(f_{i j}\right)_{\text {max }}-\left(f_{i j}\right)_{\text {min }}\right)\right]\right\} \\
i=1,2, \ldots A
\end{gathered}
$$

For beneficial criteria that always require higher values, the equation is applied. But for non-beneficial criteria the desired lower values, terminology $\left[\left(f_{i j}\right)_{\max }-f_{i j}\right]$ in the expression will be replaced with $\left[f_{i j}-\left(f_{i j}\right)_{\min }\right]$. Therefore, for the non-beneficial criteria, the equation will be reformatted as:

$$
S_{i}=L_{1, i}=\sum_{j=1}^{A}\left[w_{j}\left(f_{i j}-\left(f_{i j}\right)_{\min }\right) /\left(\left(f_{i j}\right)_{\max }-\left(f_{i j}\right)_{\min }\right)\right]
$$

Step 4: Calculate $Q_{i}$.

$$
Q_{i}=v *\left(\frac{\left(S_{i}-S_{i-\min }\right)}{S_{i-\max }-S_{i-\min }}\right)+(1-v) *\left(\frac{\left(R-R_{i-\min }\right)}{R_{i-\max }-R_{i-\min }}\right)
$$

where $S_{i-\max }$ and $S_{i-\min }$ turn are the maximum and minimum value of $S_{i}$ and $R_{i-\max }$ and $R_{i-\min }$ turn are the maximum and minimum value of $R_{i}$. With $v$ as the weight of the strategy with most attributes, (or maximum interest group, regression). Its value ranges from 0 to 1 . Typically, the value of $v$ is 0.5 to be preferred. A compromise can be selected with "vote by majority" $(v>0.5)$, with "consensus" $(v=0.5)$ or with vector $(v<0.5)$.

Step 5: Sort the choices based on the list that has the results after calculating in the previous step. Sort the alternatives in ascending order, according to the values of $S, R$, and $Q$. The result is a ranking list, in the ranking list based on increasing values of $Q$, a' $A$ compromise solution (with a minimum $Q$ value) if the following two conditions are met as follows:

C1: Acceptable advantage.

$\mathrm{Q}\left(a^{\prime \prime}\right)-\mathrm{Q}\left(a^{\prime}\right) \mathrm{DQ}$ where $a^{\prime}$ 'is the second best alternative in the ranking list by $\mathrm{Q}$ and $\mathrm{DQ}=1 /(\mathrm{N}-1)$. C2: Stability is acceptable when making decisions. 
Alternative $a^{\prime}$ must also be rated best by S or/and R. If any of the above conditions is not met, then a proposed set of compromise solutions is as follows:

- Alternative $a^{\prime}$ and "if the condition C2 is not satisfied either

- The alternatives $a^{\prime}, a^{\prime \prime}, \ldots, a(N)$ if the condition $\mathrm{C} 1$ is not satisfied $\mathrm{Q}(a(\mathrm{~N}))-\mathrm{Q}\left(a^{\prime}\right)<\mathrm{DQ}$ for maximum $\mathrm{N}$.

\section{Case Study}

The multi-criteria decision-making problem in this study is conducted through two main stages. The first phase of FANP model is built based on the criteria of the SCOR model, after having necessary data from FANP, the output data will be the input data for the VIKOR model in the next stage. First build a network that combines the main criteria and sub-criteria. The criteria will be referenced from the SCOR model in the field of supply chain. The criteria are assessed on a fuzzy score scale, thereby using the triangle decomposition method to convert fuzzy numbers into real numbers in the pairwise comparison matrix between criteria. In the next stage, the VIKOR model is applied to the calculation, the result of the model is to rank and give an optimal supplier list.

\subsection{The Data Related to the Problem}

The main criteria and sub-criteria in the problem are presented in Table 5 through the process of document review.

Table 5. Symbol of main criteria, sub-criteria in supplier selection.

\begin{tabular}{|c|c|c|c|}
\hline Main Criteria & Symbol & Subcriteria & Symbol \\
\hline \multirow{4}{*}{ Reliability } & \multirow{4}{*}{ A } & Delivery performance & A1 \\
\hline & & Fulfill the full orders & $\mathrm{A} 2$ \\
\hline & & Quantity delivered on an entire order & A3 \\
\hline & & Quality of goods & A4 \\
\hline \multirow{3}{*}{ Responsiveness } & \multirow{3}{*}{ B } & Total response time to customers & B1 \\
\hline & & Delivery time & B2 \\
\hline & & Return products time & B3 \\
\hline \multirow{3}{*}{ Ability } & \multirow{3}{*}{$\mathrm{C}$} & Ability to meet delivery demand & $\mathrm{C} 1$ \\
\hline & & Ability to receive returns products & $\mathrm{C} 2$ \\
\hline & & Ability to produce new raw materials & $\mathrm{C} 3$ \\
\hline \multirow{3}{*}{ Costs } & \multirow{3}{*}{$\mathrm{D}$} & Material cost & D1 \\
\hline & & Maintenance cost & D2 \\
\hline & & Transportation costs & D3 \\
\hline \multirow{4}{*}{ Asset management Efficiency } & \multirow{4}{*}{$\mathrm{E}$} & Financial situation of suppliers & E1 \\
\hline & & Payment term allowed & E2 \\
\hline & & Revenue over a year & E3 \\
\hline & & Inventory amount of suppliers & E4 \\
\hline
\end{tabular}

Along with the main and secondary criteria, the next data of the problem is the material supplier; Table 6 below lists the selected suppliers.

Table 6. List of material suppliers.

\begin{tabular}{cccccc}
\hline No. & Supplier & Symbol & No. & Supplier & Symbol \\
\hline 1 & Supplier 1 & NCU1 & 6 & Supplier 6 & NCU6 \\
2 & Supplier 2 & NCU2 & 7 & Supplier 7 & NCU7 \\
3 & Supplier 3 & NCU3 & 8 & Supplier 8 & NCU8 \\
4 & Supplier 4 & NCU4 & 9 & Supplier 9 & NCU9 \\
5 & Supplier 5 & NCU5 & 10 & Supplier 10 & NCU10 \\
\hline
\end{tabular}


After collecting all necessary criteria and suppliers, fuzzy assessment matrix related to the target is given in Table 7. The decision-maker then compares the attributes associated with the criteria. The pairwise comparison matrices are performed and the weight vector of each matrix is calculated.

From Table 7, we can see Table 8 of the matrix comparing pairs of main criteria with fuzzy numbers as above. To convert fuzzy numbers into real numbers, we solve the fuzzy problem using the triangle fuzzy numerical method. In the defrosting process, we take coefficients $\alpha=0.5$ and $\beta=0.5$. In which, $\alpha$ represents an uncertain environment, $\beta$ shows that the assessor's attitude is fair [52,53]. We have:

$$
\begin{gathered}
t_{0.5,0.5}\left(\bar{a}_{B, C}\right)=[(0.5 \times 2.5)+(1-0.5) \times 3.5]=3 \\
g_{0.5}\left(L_{B, C}\right)=(3-2) \times 0.5+2=2.5 \\
g_{0.5}\left(U_{B, C}\right)=4-(4-3) \times 0.5=3.5 \\
t_{0.5,0.5}\left(\bar{a}_{C, B}\right)=1 / 3
\end{gathered}
$$

The remaining cells are calculated similarly as above, as well as the priority scale of the fuzzy number. The priority is equal to the real number when comparing the pair of main criteria presented in Table 9.

To calculate the maximum private value $\lambda_{\max }$ and weight $\omega$ of the matrix we apply the formula:

$$
\begin{aligned}
& \text { GM1 }(B)=(1 \times 3 \times 1 / 3 \times 1 / 2 \times 2)^{1 / 5}=1.000 \\
& \text { GM2 }(C)=(1 / 3 \times 1 \times 1 / 2 \times 1 / 4 \times 1 / 2)^{1 / 5}=0.461 \\
& \text { GM3 }(A)=(3 \times 2 \times 1 \times 1 / 3 \times 4)^{1 / 5}=1.516 \\
& \text { GM4 }(\mathrm{D})=(2 \times 4 \times 3 \times 1 \times 3)^{1 / 5}=2.352 \\
& \text { GM5 }(\mathrm{E})=(1 / 2 \times 2 \times 1 / 4 \times 1 / 3 \times 1)^{1 / 5}=0.608 \\
& \Sigma \mathrm{GM}=\mathrm{GM} 1+\mathrm{GM} 2+\mathrm{GM} 3+\mathrm{GM} 4+\mathrm{GM} 5 \\
& =1.000+0.461+1.516+2.352+0.608=5.937 \\
& \omega_{1}=\frac{1.000}{5.937}=0.168 \\
& \omega_{2}=\frac{0.461}{5.937}=0.078 \\
& \omega_{3}=\frac{1.515}{5.937}=0.255 \\
& \omega_{4}=\frac{2.352}{5.937}=0.396 \\
& \omega_{5}=\frac{0.608}{5.937}=0.102 \\
& {\left[\begin{array}{ccccc}
1 & 3 & 1 / 3 & 1 / 2 & 2 \\
1 / 3 & 1 & 1 / 2 & 1 / 4 & 1 / 2 \\
3 & 2 & 1 & 1 / 3 & 4 \\
2 & 4 & 3 & 1 & 3 \\
1 / 2 & 2 & 1 / 4 & 1 / 3 & 1
\end{array}\right] \times\left[\begin{array}{l}
0.168 \\
0.078 \\
0.255 \\
0.396 \\
0.102
\end{array}\right]=\left[\begin{array}{l}
0.890 \\
0.412 \\
1.458 \\
2.117 \\
0.538
\end{array}\right]} \\
& {\left[\begin{array}{l}
0.890 \\
0.412 \\
1.458 \\
2.117 \\
0.538
\end{array}\right] /\left[\begin{array}{l}
0.168 \\
0.078 \\
0.255 \\
0.396 \\
0.102
\end{array}\right]=\left[\begin{array}{l}
5.298 \\
5.282 \\
5.718 \\
5.346 \\
5.275
\end{array}\right]}
\end{aligned}
$$


The number of criteria is 5 , so we have $n=5, \lambda_{\max }$ and CI value is calculated as follows:

$$
\begin{gathered}
\lambda_{\max }=\frac{5.298+5.282+5.718+5.346+5.275}{5}=5.384 \\
C I_{C}=\frac{\lambda_{\max }-N}{N-1}=\frac{5.384-5}{5-1}=0.096
\end{gathered}
$$

To calculate CR, for $n=5$, take $\mathrm{RI}=1.12$

$$
C R_{C}=\frac{C I_{C}}{R I}=\frac{0.096}{1.12}=0.086
$$

We have a consistency ratio $\mathrm{CR}=0.086 \leq 0.1$, so the data comparing the main criteria pairs are appropriate and do not need to be reevaluated.

The results of FANP model are shown in Table 10.

The VIKOR model was developed to select the appropriate supplier. Results show that:

In $\mathrm{C} 1$, the second best option in the ranking list is that NCU3 did not satisfy the requirements. Therefore, in C2 a proposed set of compromise solutions is a search for suppliers ranked in descending order.

Provided DQ set out in C2 we have a supplier list including:

- $\quad$ DQ not eligible suppliers include: NCU4, NCU3, NCU6.

- $\quad$ DQ eligible suppliers from low to high: NCU5, NCU1, NCU8, NCU7, NCU2, NCU10, NCU9.

Provided that $\mathrm{DQ}=0.111$. Suppliers are ranked in descending order in the rankings. Table 11 shows the ranking results. 
Table 7. Compare pairs of the main criteria.

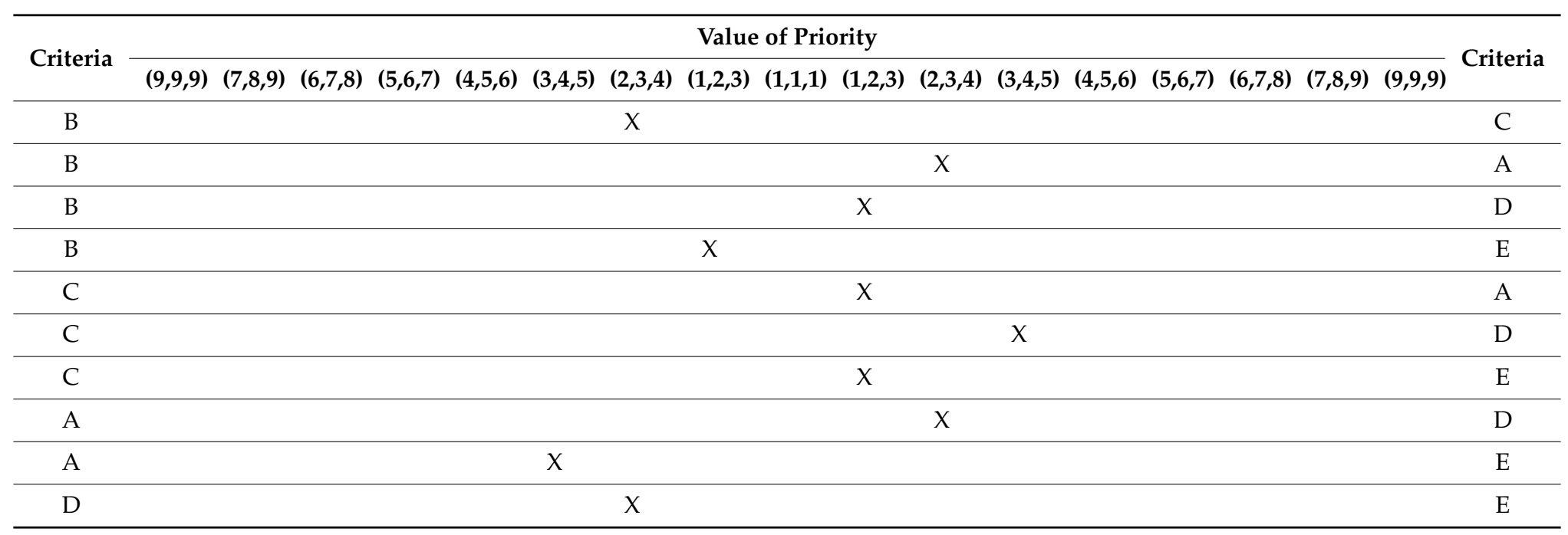


Table 8. Matrix of comparing pairs between main criteria by fuzzy numbers.

\begin{tabular}{cccccc}
\hline Criteria & B & C & A & D & E \\
\hline B & $(1,1,1)$ & $(2,3,4)$ & $(1 / 4,1 / 3,1,2)$ & $(1 / 3,1 / 2,1)$ & $(1,2,3)$ \\
C & $(1 / 4,1 / 3,1,2)$ & $(1,1,1)$ & $(1 / 3,1 / 2,1)$ & $(1 / 5,1 / 4,1 / 3)$ & $(1 / 3,1 / 2,1)$ \\
A & $(2,3,4)$ & $(1,2,3)$ & $(1,1,1)$ & $(1 / 4,1 / 3,1,2)$ & $(3,4,5)$ \\
D & $(1,2,3)$ & $(3,4,5)$ & $(2,3,4)$ & $(1,1,1)$ & $(2,3,4)$ \\
E & $(1 / 3,1 / 2,1)$ & $(1,2,3)$ & $(1 / 5,1 / 4,1 / 3)$ & $(1 / 5,1 / 4,1 / 3)$ & $(1,1,1)$ \\
\hline
\end{tabular}

Table 9. Matrix of comparing pairs between main criteria by real numbers.

\begin{tabular}{cccccc}
\hline Criteria & B & C & A & D & E \\
\hline B & 1 & 3 & $1 / 3$ & $1 / 2$ & 2 \\
C & $1 / 3$ & 1 & $1 / 2$ & $1 / 4$ & $1 / 2$ \\
A & 3 & 2 & 1 & $1 / 3$ & 4 \\
D & 2 & 4 & 3 & 1 & 3 \\
E & $1 / 2$ & 2 & $1 / 4$ & $1 / 4$ & 1 \\
\hline
\end{tabular}

Table 10. Result of ranking the priority of the secondary criteria.

\begin{tabular}{ccc}
\hline No & Subcriteria & Weight \\
\hline 1 & A1 & 0.061 \\
2 & A2 & 0.022 \\
3 & A3 & 0.050 \\
4 & A4 & 0.134 \\
5 & B1 & 0.036 \\
6 & B2 & 0.113 \\
7 & B3 & 0.015 \\
8 & C1 & 0.048 \\
9 & C2 & 0.007 \\
10 & C3 & 0.022 \\
11 & D1 & 0.224 \\
12 & D2 & 0.030 \\
13 & D3 & 0.141 \\
14 & E1 & 0.021 \\
15 & E2 & 0.017 \\
16 & E3 & 0.007 \\
17 & E4 & 0.053 \\
\hline
\end{tabular}

Table 11. Ranking of supplier compromises by value $Q_{i}$.

\begin{tabular}{ccc}
\hline Supplier & DQ Value & Ranking \\
\hline NCU9 & 0.846 & 1 \\
NCU10 & 0.744 & 2 \\
NCU2 & 0.744 & 3 \\
NCU7 & 0.653 & 4 \\
NCU8 & 0.584 & 5 \\
NCU1 & 0.531 & 6 \\
NCU5 & 0.125 & 7 \\
NCU6 & 0.017 & 8 \\
NCU3 & 0.025 & 9 \\
NCU4 & 0.000 & 10 \\
\hline
\end{tabular}

\subsection{Results and Discussion}

In today's supply chain management, the performance of potential suppliers is assessed through multiple criteria rather than just cost factors. Choosing a supplier opens up new unconditional perspectives toward better resource allocation, minimizing the risks associated with purchasing and 
reducing costs by saving time, money, and effort. There is no standard supplier assessment even though a number of decision-making methods have been developed to help the supplier selection process, since each method has its own advantages for the company, so companies will use the one that best suits their industry and expectations.

The application of the SCOR method helps to develop a set of criteria, which is a prerequisite for FANP to evaluate weights for selected criteria, and VIKOR helps to make decisions on selecting the most appropriate suppliers. VIKOR helps to exploit the advantages of FANP and take advantage of the shortcomings that FANP omits. VIKOR has optimally synchronized among criteria and suppliers, establishing an accurate set of weights after fuzzy solvers, and overcoming the subjective weaknesses of the FANP model when assessing suppliers based on weight data and questionnaires only. The VIKOR model uses FANP's output data set as an input to a quantitative model that makes it easy to understand and implement for calculations and produces clear results that help optimize potential suppliers from the model. FANP image was omitted. This quantitative research is also of a survey nature and is used to help develop a clear understanding of a situation.

The FANP-VIKOR method not only results in reasonable results but also allows the decision-maker to visualize the impact of different criteria in the final result. Therefore, this integrated model may offer valuable insights as well as provide methods for other sectors to select and evaluate suppliers.

\section{Conclusions}

The cost of raw materials accounts for about $70-80 \%$ of the product cost, which makes it difficult for domestic businesses to compete with other similar export countries. Selection of plastics raw material suppliers, which is the first step in the product implementation process, starting from the purchase of raw materials to the end of product delivery, is considered to be a deciding factor for companies looking forward to success in today's competitive conditions. The process of plastic raw material supplier selection can be considered as multicriteria decision-making (MCDM) to find an optimal solution for supplier selection.

Many studies have applied the MCDM approach to various fields of science and engineering and their number has been increasing over the past years. One of the fields that the fuzzy MCDM model save been applied to is supplier selection problem. Although some studies have considered a review of applications of MCDM approaches in this field, very few work has focused on this problem in a fuzzy environment. This is the reason why hybrid ANP with fuzzy logic and VIKOR is proposed in this study.

In this study, the proposed model provides a new approach for decision-makers in evaluating and selecting suppliers, which is formulated based on the supply chain operation reference (SCOR) model, fuzzy analytic network process (FANP), and VIseKriterijumska Optimizacija I Kompromisno Resenje (VIKOR).

The contribution of this research is to propose a multicriteria decision-making model (MCDM) for supplier selection in plastic industry. This research also provided a useful guideline for supplier selection in other industry.

For improving these MCDM model, outlier detection and the curse of dimensionality of DEA model will be considered in future research. Moreover, different methodologies, such like fuzzy data envelopment analysis (FDEA), FAHP ... , can also been combined for different scenarios.

Author Contributions: Conceptualization, C.-N.W., V.T.N. and T.-F.L.; formal analysis, J.-T.C.; funding acquisition, C.-N.W., J.-T.C., and V.T.N.; investigation, V.T.N.; methodology, C.-N.W., V.T.N., T.-F.L. and T.N.N.; project administration, J.-T.C., and T.N.N.; resources, C.-N.W. and T.-F.L.; software, V.T.N. T.-F.L. and T.N.N.; supervision, V.T.N.; writing—original draft, V.T.N. and T.-F.L.; writing—review and editing, C.-N.W., J.-T.C., V.T.N., and T.N.N.

Funding: This research was partly supported by National Kaohsiung University of Science and Technology, and project number 108-2622-E-992-017-CC3 from the Ministry of Sciences and Technology in Taiwan.

Conflicts of Interest: The authors declare no conflict of interest. 


\section{References}

1. Hiep Hoi Nhua Viet Nam (VPAS). Báo cáo tổng quan ngành nhựa Việt Nam 2015-2018; FBT Company: Ho Chi Minh, Vietnam, 2018.

2. Gencer, C.; Gurpinar, D. Analytic network process in supplier selection: A case study in an electronic firm. Appl. Math. Model. 2007, 31, 2475-2486. [CrossRef]

3. Venkateswarlu, P.; Sarma, B.D. Selection of Supplier by Using Saw and Vikor Methods. J. Eng. Res. Appl. 2016, 6, 80-88.

4. Zadeh, L. Fuzzy Set. Inf. Control 1965, 8, 338-353. [CrossRef]

5. Hsu, C.W.; Kuo, R.J.; Chiou, C.Y. A multi-criteria decision making approach for evaluating carbon performance of suppliers in the electronics industry. Int. J. Environ. Sci. Technol. 2014, 11, 775-784. [CrossRef]

6. Ou Yang, Y.P.; Shieh, H.M.; Tzeng, G.H. A novel hybrid MCDM model combined with DEMATEL and ANP with applications. Int. J. Oper. Res. 2008, 5, 160-168.

7. Shemshadi, A.; Shirazi, H.; Toreihi, M.; Tarokh, M.J. A fuzzy VIKOR method for supplier selection based on entropy measure for objective weighting. Exp. Syst. Appl. 2011, 38, 12160-12167. [CrossRef]

8. Lambert, D.M. Supply Chain Management: Processes, Partnerships, Performance; Supply Chain Management Institute: Tempe, AZ, USA, 2008.

9. Bolstorff, P.; Rosenbaum, R.G. Supply Chain Excellence: A Handbook for Dramatic Improvement Using the SCOR; AMACOM: New York, NY, USA, 2012.

10. Huan, S.H.; Sheoran, S.K.; Wang, G. A review and analysis of supply chain operations reference (SCOR) model. Supply Chain Manag. 2004, 9, 23-29. [CrossRef]

11. Wang, C.-N.; Huang, Y.-F.; Cheng, I.-F.; Nguyen, V.T. A Multi-Criteria Decision-Making (MCDM) Approach Using Hybrid SCOR Metrics, AHP, and TOPSIS for Supplier Evaluation and Selection in the Gas and Oil Industry. Processes 2018, 6, 252. [CrossRef]

12. Florez-Lopez, R. Strategic supplier selection in the added-value perspective: A CI approach. Inf. Sci. 2007, 177, 1169-1179. [CrossRef]

13. Lima-Junior, F.R.; Carpinetti, L.C.R. Combining SCORßmodel and fuzzy TOPSIS for supplier evaluation and management. Int. J. Prod. Econ. 2016, 174, 128-141. [CrossRef]

14. Palma-Mendoza, J.A. Analytical hierarchy process and SCOR model to support supply chain re-design. Int. J. Inf. Manag. 2014, 34, 634-638. [CrossRef]

15. Lima-Junior, F.R.; Ribeiro, C.L.C. Predicting supply chain performance based on SCOR ${ }^{\circledR}$ metrics and multilayer perceptron neural networks. Int. J. Prod. Econ. 2019, 212, 19-38. [CrossRef]

16. Huang, S.H.; Sheoran, S.K.; Keskar, H.K. Computer-assisted supply chain configuration based on supply chain operations reference (SCOR) model. Comput. Ind. Eng. 2005, 48, 377-394. [CrossRef]

17. Wang, C.-N.; Nguyen, V.T.; Thai, H.T.N.; Tran, N.N.; Tran, T.L.A. Sustainable Supplier Selection Process in Edible Oil Production by a Hybrid Fuzzy Analytical Hierarchy Process and Green Data Envelopment Analysis for the SMEs Food Processing Industry. Mathematics 2018, 6, 302. [CrossRef]

18. Nazim, R.; Yahya, S.; Malim, M.R. A New Approach to Supplier Selection Problem: An Introduction of AHP-SCOR Integrated Model. Int. J. Recent Innov. Trends Comput. Commun. 2015, 3, 338-346. [CrossRef]

19. BaniBukhori, I.; Widodo, K.H.; Ismoyowati, D. Evaluation of Poultry Supply Chain Performance in XYZ Slaughtering House Yogyakarta Using SCOR and AHP Method. Agric. Agric. Sci. Proc. 2015, 3, 221-225.

20. Thilakarathna, R.H.; Dharmawardana, M.N.; Rupasinghe, T. The Supply Chain Operations Reference (SCOR) model: A Systematic Review of Literature from the Apparel Industry. In Proceedings of the 12th International Conference on Business Management, Abu Dhabi, UAE, 7-8 December 2015.

21. Cuong, N.H.; Cuong, B.C.; Phuoc, N.D.; Minh, P.X.; Van Hy, C. Hệ Mờ Và Úng Dụng; Nhà Xuất Bản Khoa Học Và Kỹ Thuật: Hà Nội năm, Vietnam, 1998.

22. HarpreetSingh, M.M.G.; Meitzler, T.; Hou, Z.-G.; Garg, K.K.; Solo, A.M.G.; Zadeh, L.A. Real-Life Applications of Fuzzy Logic. Adv. Fuzzy Syst. 2013, 2013. [CrossRef]

23. Phong, N.N.; Mo, V.T. NXB Đại Học Quốc Gia TP; HCM: Ho Chi Minh, Vietnam, 2010.

24. Evans, A. A Theoretical Comparison of Competition with Other Economic Regimes for Bus Services. J. Transp. Econ. Policy 1987, 21, 7-36.

25. Biao, S.; Nutman, A.P.; Dunyi, L.; Jiashan, W. 3800 to 2500, Matrix Crustal Evolution in the Anshan Area of Liaoning Province, Northeastern China. Precambrian Res. 1996, 78, 79-94. 
26. Yang, J.; Edwards, D.J.; Love, P.E.D. A computational intelligent fuzzy model approach for excavator cycle time simulation. Autom. Constr. 2003, 12, 725-735. [CrossRef]

27. Saaty, T.L. Decision Making with Dependence and Feedback: The Analytic Network Process; RWS Publications: Pittsburgh, PA, USA, 1996.

28. Yilmaz, O.F.; Oztaysi, B.; Durmusoglu, M.B.; Oner, S.C. Determination of Material Handling Equipment for Lean In-Plant Logistics Using Fuzzy Analytical Network Process Considering Risk Attitudes of the Experts. Int. J. Ind. Eng. 2017, 24, 81-122.

29. Khal, S.; Safaei, A. Using Fanp and Fuzzy Vikor for Ranking Manufacturing Companies Based on Their Financial Performance. Econ. Cybern. 2014, 48, 287-308.

30. Wang, C.; Nguyen, V.T.; Duong, D.H.; Do, H.T. A Hybrid Fuzzy Analytic Network Process (FANP) and Data Envelopment Analysis (DEA) Approach for Supplier Evaluation and Selection in the Rice Supply Chain. Symmetry 2018, 10, 221. [CrossRef]

31. Opricovic, S. Programski Paket VIKOR za Visekriterijumsko Kompromisno Rangiranje; SYM-OP-IS: Belgrade, Serbia, 1990.

32. Duckstein, L.; Opricovic, S. Multiobjective Optimization in River Basin Development. Water Resour. Res. 1980, 16, 14-20. [CrossRef]

33. Yu, P.L. A class of solutions for group decision problems. Manag. Sci. 1973, 19, 936-946. [CrossRef]

34. Zeleny, M. Multiple Criteria Decision Making; Mc-Graw-Hill: New York, NY, USA, 1982.

35. Chatterjee, P.; Chakraborty, S. A comparative analysis of VIKOR method and its variants. Q. Publ. 2016, 5, 469-486. [CrossRef]

36. Opricovic, S.; Tzeng, G.-H. Extended VIKOR method in comparison with outranking methods. Eur. J. Oper. Res. 2007, 178, 514-529. [CrossRef]

37. Kuo, M.-S.; Liang, G.-S. Combining VIKOR with GRA techniques to evaluate service quality of airports under fuzzy environment. Expert Syst. Appl. 2011, 38, 1304-1312. [CrossRef]

38. Jeya Girubha, R.; Vinodh, S. Application of fuzzy VIKOR and environmental impact analysis for material selection of an automotive component. Mater. Des. 2012, 37, 478-486. [CrossRef]

39. Gorla, N.; Chinta, R.; Chu, T.W. An enhanced business process re-engineering model for supply chain management and a case study. J. Inf. Technol. Case Appl. Res. 2007, 9, 5-27. [CrossRef]

40. Govinda, K.; Jarendan, S.; Sarkis, J.; Murugesan, P. MCDM Approaches for Green Supplier Evalution and Selection: A Literature Review. J. Clean. Prod. 2015, 98, 66-83.

41. Pun, L.; Doumeingts, G.; Grislain, J.; Breuil, D. A Survey on Computer-Aided Planning in Complicate Production Systems. Ifac Proc. Vol. 1980, 13, lv-lxxvii. [CrossRef]

42. Charles, A.; Current, W.J.R.; Benton, W.C. Vendor selection criteria and methods. Eur. J. Oper. Res. 1991, 50, 2-18.

43. Dargia, A.; Anjomshoaea, A.; Galankashia, M.R.; Memaria, A.; Md Tapa, M.B. Supplier Selection: A Fuzzy-ANP Approach. Proc. Comput. Sci. 2014, 31, 691-700. [CrossRef]

44. Erdebilli, B.; Erkan, T.E. Selecting the best supplier using analytic hierarchy process (AHP) method. Afr. J. Bus. Manag. 2012, 6, 1455-1462.

45. Jahan, A.; Mustapha, F.; Ismail, M.Y.; Sapuan, S.M.; Bahraminasab, M. A comprehensive VIKOR method for material selection. Mater. Des. 2011, 32, 1215-1221. [CrossRef]

46. Wu, M.; Liu, Z. The supplier selection application based on two methods: VIKOR algorithm with entropy method and Fuzzy TOPSIS with vague sets method. Int. J. Manag. Sci. Eng. Manag. 2011, 6, 109-115. [CrossRef]

47. Piasecki, K.; Roszkowska, E. On application of ordered fuzzy numbers in ranking linguistically evaluated negotiation offers. Adv. Fuzzy Syst. 2018, 2018, 1569860. [CrossRef]

48. Wang, B.; Song, J.; Ren, J.; Li, K.; Duan, H.; Wang, X. Selecting sustainable energy conversion technologies for agricultural residues: A fuzzy AHP-VIKOR based prioritization from life cycle perspective, Resources. Conserv. Recycl. 2019, 142, 78-87. [CrossRef]

49. Abdel-Baset, M.; Chang, V.; Gamal, A.; Smarandache, F. An integrated neutrosophic ANP and VIKOR method for achieving sustainable supplier selection: A case study in importing field. Comput. Ind. 2019, 106, 94-110. [CrossRef]

50. Cheng, S.-H.; Chen, S.-M.; Huang, Z.-C. Autocratic decision making using group recommendations based on ranking interval type-2 fuzzy sets. Inf. Sci. 2016, 361, 135-161. [CrossRef] 
51. Liu, K.; Liu, Y.; Qin, J. An Integrated ANP-VIKOR Methodology for Sustainable Supplier Selection with Interval type-2 Fuzzy Sets. Granul. Comput. 2018, 3, 193-208. [CrossRef]

52. Beyon, Y.C.; Tang, M.J. Group decision making within capital investment: A Fuzzy Analytic Hierarchy Process approach with developments. Int. J. Oper. Res. 2009, 4, 75-96.

53. Beyon, Y.C.; Tang, M.J. Application and Development of a Fuzzy Analytic Hierarchy Process within a Capital Invesment Study. J. Econ. Manag. 2005, 2, 207-230. 